\title{
RESEARCH
}

\section{TooT-SC: Predicting Eleven Substrate Classes o Transmembrane Transport Proteins}

\author{
Munira Alballa ${ }^{1,2}$ and Gregory Butler ${ }^{1,3^{*}}$
}

\footnotetext{
${ }^{*}$ Correspondence:

gregory.butler@concordia.ca

${ }^{1}$ Department of Computer Science

and Software Engineering,

Concordia University, Montreal,

Canada
}

Full list of author information is

available at the end of the article

\begin{abstract}
Background: Transporters form a significant proportion of the proteome and play an important rol in mediating the movement of compounds across membranes. Transport proteins are difficult to characterize experimentally, so there is a need for computational tools that predict the substrates transported in order to annotate the large number of genomes being sequenced. Recently we developed a dataset of eleven substrate classes from Swiss-Prot using the ChEBI ontology as the basis for the definition of the classes.

Results: We extend our earlier work TranCEP, which predicted seven substrate classes, to the nel dataset with eleven substrate classes. Like TranCEP, TooT-SC combines pairwise amino acid composition (PAAC) of the protein, with evolutionary information captured in a multiple sequence alignment (MSA) using TM-Coffee, and restriction to important positions of the alignment using TCS. Our experimental results show that TooT-SC significantly outperforms the state-of-the-art predictors, including our earlier work, with an overall MCC of 0.82 and the MCC for the eleven classes ranging from 0.66 to 1.00 .

Conclusion: TooT-SC is a useful tool with high performance covering a broad range of substrate classes. The results quantify the contribution made by each type of information used during the prediction process. We believe the methodology is applicable more generally for protein sequence analysis.

Keywords: protein sequence analysis; evolutionary information; positional information; regional information; sequential information; compositional information; transport proteins; substrate class classification
\end{abstract}




\section{Background}

Transport proteins play important roles in biological processes [1] and form a large proportion of all proteins in an organism [2], yet existing tools for the annotation of transporters that predict the substrates of transport reactions lag behind tools for other kinds of proteins, such as for predicting enzymes involved in metabolic reactions. Many tools rely simply on homology or orthology to predict transporters. These tools include the metabolic network tools merlin [3-5], Pantograph [6], and TransATH [7] that process the complete proteome and predict each transport reaction, which means identifying the transport protein and the specific substrate, as well as cellular compartment.

Among the tools for de novo prediction of substrate class, FastTrans [8] claims to be the state-of-the-art. The de novo prediction tools predict the type of substrate from a general subset of substrate types, without attempting to predict the specific substrate [9-13], due to the limited number of transporters annotated with specific substrates. Until now, these tools have reached a maximum of seven substrate types [13] [8].

In 2019 we developed a dataset [14] that defined substrate classes in terms of the ChEBI ontology for Chemical Entities of Biological Interest [15]. Transporters in Swiss-Prot that have' GO annotations of functional transport activity of a substrate contain a link to the ChEBI term for the particular substrate as part of the GO term. The ChEBI hierarchy allowed us to group substrates into classes giving us eleven well-defined classes with sufficient number of examples for machine learning. To the best of our knowledge, these data contain the highest number of substrate classes being used to predict the substrate class of a transporter.

This paper extends our previous work TranCEP [16]. This work follows the same methodology, however, using the new dataset with eleven classes. As before we studied the impact of protein composition, protein evolution, and the specificity-determining positions within the protein sequence. The best approach, which defines TooT-SC, involves utilizing the PAAC encoding scheme, the TM-Coffee MSA algorithm [?], and the transitive consistency score (TCS) algorithm [17] to create vectors as input to build a suite of SVM classifiers, one for distinguishing each substrate class. The difference between the work on $\operatorname{TranCEP}$ and TooT-SC are 
- the different datasets with eleven versus seven substrate classes;

- the definition of substrate classes using the ChEBI ontology;

- using the Swiss-Prot annotation of the substrate of a transport protein rather than manual annotation by the researchers;

- building the multi-class SVM classifier as a collection of one-versus-rest binary SVM classifiers (like TrSSP [13]) rather than as one-versus-one classifiers; and

- using the SVM probabilities to classify a test protein.

Readers seeking more background on work in this area, and the details of the methodology are referred to our previous paper on $\operatorname{Tran} C E P$ [16] and the $\mathrm{PhD}$ thesis [18] of the first author.

\section{Materials and Methods}

\section{Dataset}

The dataset was constructed from Swiss-Prot using the ChEBI ontology [15] as described in [14]. The dataset contains 11 substrate classes, with the largest being the inorganic cations class with 601 samples and the smallest being the nucleotide class with 24 samples, as presented in Table 1 . The data were randomly partitioned (stratified by class) into training (90\%) and testing (10\%) sets. We refer to the data in Table 1 as $D S-S C$.

\section{Databases}

We used the same databases as before: Swiss-Prot database when searching for similar sequences; and the UniRef50-TM database, which consists of the entries in UniRef50 that have the keyword transmembrane, inside TM-Coffee [19] when constructing MSAs. Since dataset was derived from Swiss-Prot, we removed the exact hits of test sequences from the two databases Swiss-Prot and UniRef50-TM.

\section{Algorithm}

Algorithm 1 presents the template for constructing the vectors required for the SVM classifiers. It combines evolutionary $(\mathrm{E})$, positional $(\mathrm{P})$, and compositional $(\mathrm{C})$ information. The first two are optional. We used TM-Coffee to compute the MSA that conserves the TMSs and the TCS to 
determine a reliability index for each position (column) in the MSA. We experimented with three composition schemes, AAC, PAAC, and PseAAC, as well as the optional use of TM-Coffee and the TCS.

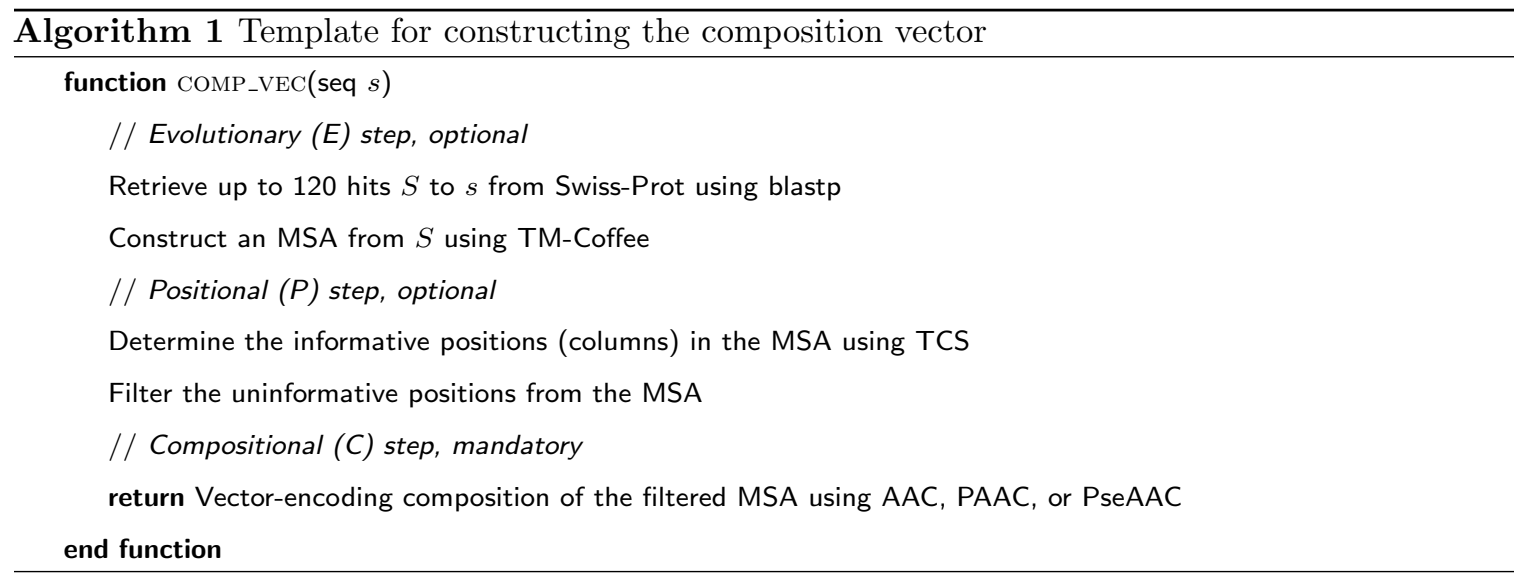

Algorithm 2 shows the composition vectors being used to build a set of SVM classifiers. In this case, multi-class classification is done using a collection of binary classifiers as one-versus-rest for each of the eleven classes.

Algorithm 3 presents the prediction algorithm. Here we use the probability of each class prediction as returned by the SVM to determine the classification.

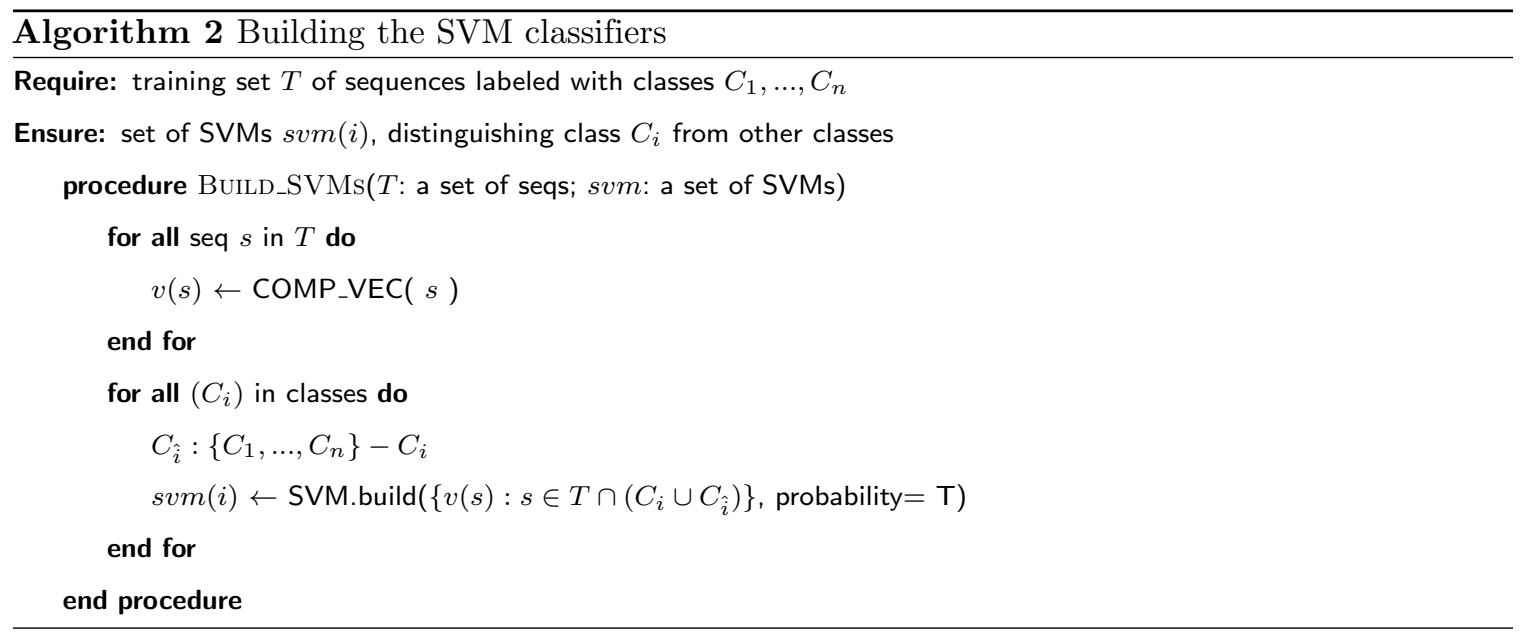




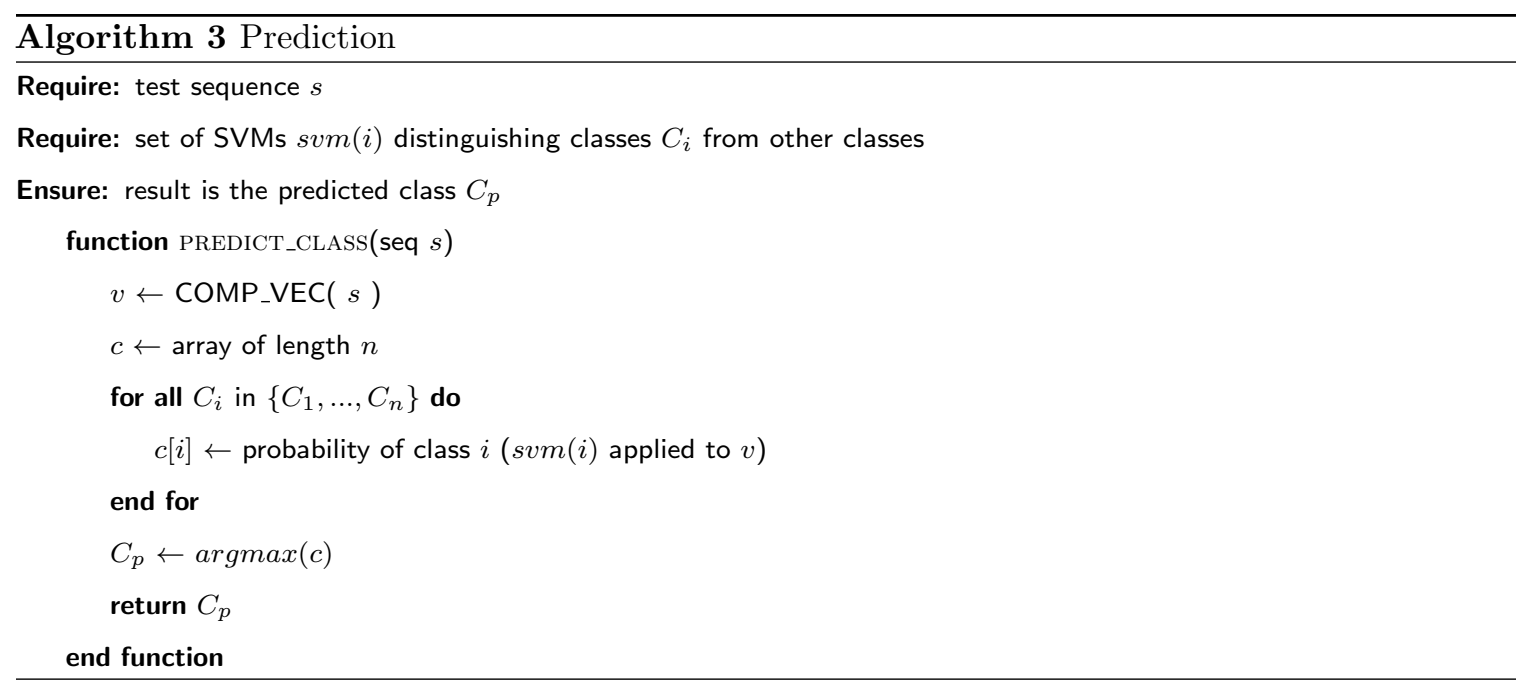

\section{Training}

We used SVM with an RBF kernel, as implemented in the R e1071 library (version 1.6-8), utilizing a one-against-the-rest approach in which $n$ binary classifiers are trained, one for each class. The classifier $i$ is trained with all the samples of class $i$ as a positive class and the rest as a negative class. The final predicted class is the class with the highest probability among the $n$ predictions. Both the cost and $\gamma$ parameters of the RBF kernel were optimized by performing a grid search using the tune function in the library (cost range: $2^{(1 \ldots 5)}, \gamma$ range: $2^{(-18 \ldots 2)}$ ).

\section{Methods}

We experimented with nine methods with different combinations of inforamation:

- AAC, PAAC, and PseAAC using only compositional information;

- TMC-AAC, TMC-PAAC, and TMC-PseAAC using evolutionary and compositional information; and

- TMC-TCS-AAC, TMC-TCS-PAAC, and TMC-TCS-PseAAC using evolutionary, positional, and compositional information.

The method used in TooT-SC is TMC-TCS-PAAC, the method that achieved the best performance during cross-validation. 


\section{Performance evaluation}

The performance of each method on the $D S-S C$ training set was determined using ten-fold cross-validation (10-CV). We repeated the $10-\mathrm{CV}$ process ten times with different random partitions, to make the error estimation more stable, and reported the performance variations between the runs by computing the standard deviation.

Four performance metrics were considered:

$$
\begin{aligned}
\text { Sensitivity } & =\frac{T P}{T P+F N} \\
\text { Specificity } & =\frac{T N}{T N+F P} \\
\text { Accuracy } & =\frac{T P+T N}{T P+F N+T N+F P} \\
\mathrm{MCC} & =\frac{(T P \times T N-F P \times F N)}{\sqrt{(T P+F P) \times(T P+F N) \times(T N+F P) \times(T N+F N)}}
\end{aligned}
$$

where $T P$ is the number of true positives, $T N$ is the number of true negatives, $F P$ is the number of false positives, and $F N$ is the number of false negatives.

The Matthews Correlation Coefficient (MCC) is less influenced by imbalanced data and is arguably the best single assessment metric in this case [20-22]. The overall performance across all classes was the micro-average of the individual results due to the imbalanced dataset.

\section{Statistical analysis}

In this analysis, Student's (two-tailed, paired) t-tests were applied, and the average number of informative residues, as determined by TCSs, in different segments of a protein sequence was computed. For each substrate class, pairwise comparisons between the means of important positions in different segments were performed. The differences were considered statistically significant when the P-value of the Student's t-test was less than 0.0001 . 


\section{Results and Discussion}

\section{Methods evaluation}

Since the data are imbalanced, we focused on the MCC when comparing the performances of the different models. Table 2 presents the overall accuracy values and MCCs of the SVM models for the nine methods, sorted from the best to the worst according to the MCC. The details of the performance for each method are available in Supplementary Material 1. the comparisons among the different methods for the eleven classes in terms of the MCC are presented in Figure 1. The SVM model that utilized PAAC encoding outperformed those that utilized AAC and PseAAC encoding by $27 \%$ and $15 \%$, respectively, in terms of the overall MCCs. This model shows exceptionally high performance in the water and nucleotide classes. In addition, all of the SVM models that utilized evolutionary data performed notably better overall than the SVM models that did not. The top model, TMC-TCS-PAAC, which is the method chosen for our predictor $\mathbf{T o o} \boldsymbol{T}$ - $\boldsymbol{S C}$, incorporates the use of the PAAC with evolutionary data in the form of MSA with positional information, in which columns that have a reliability below 4 are filtered out. We found that the performance peaked using this threshold and started to decline when columns with a reliability index greater than 4 were filtered out. The TMC-TCS-PAAC method yielded an overall MCC of 0.77 during cross-validation. Table 4 shows the impact of evolutionary information and positional information on the composition-encoding PAAC.

The use of evolutionary information in the form of MSA on the composition-encoding PAAC showed a considerable positive impact in most of the substrate classes, where the average improvement of the MCC was $126.41 \%$, with the highest improvement being in the $\mathrm{C} 1$ (nonselective) class (347\%). The baseline encoding PAAC for the C2 (water) substrate class showed a high discriminatory power with an MCC of 0.96 , with the incorporation of additional information having a slightly negative impact of $1.01 \%$.

The further use of positional information by filtering out the unreliable columns from the MSA showed an average improvement of $128.57 \%$ compared to the baseline compositions. The impact of positional information over that already achieved by evolutionary information showed a positive 
impact in most substrate classes; the highest was in the C5 (organic anions) class, where the MCC improved by $6.38 \%$ with TMC-TCS-PAAC. However, the impact was slightly negative in the C1 (nonselective), C2 (water), C3 (inorganic cations), and C9 (nucleotides) classes.

\section{Comparison with other published work}

The top two tools with the best reported performance are TrSSP [13] and FastTrans [8]. Since the original code was not available for TrSSP or FastTrans, we reimplemented the methods to the best of our ability. We compared the performance of the TooT-SC method with our implementation of the TrSSP and FastTrans methods. All of the methods were trained using the $D S$ - $S C$ training set and tested using its testing set. It should be noted that our implementation of the TrSSP method [13] achieved a similar macroaverage MCC to that reported in the original paper $(0.41)$ on their dataset. However, it was not possible to reproduce the reported performance of the FastTrans method [8], for which our implementation on their same dataset achieved a macroaverage MCC of 0.47 , while their reported macroaverage MCC was 0.87 .

A comparison between the TooT-SC method and our implementation of the other state-of-the-art methods on the $D S$-SC benchmark dataset is presented in Table 5. The TooT-SC method scored higher than the other methods for all of the substrate classes in terms of the accuracy, sensitivity, and MCC. Overall, the TooT-SC method scored an overall MCC of 0.82 , which outperformed the TrSSP method by $26 \%$ and the FastTrans method by $115 \%$.

\section{Positional information analysis}

See Supplementary Material 2.

\section{Conclusion}

We have developed TooT-SC for the de novo prediction of substrates for membrane transporter proteins that combines information based on the amino acid composition, evolutionary information, and positional information. Too $T$ - $S C$ is able to classify transport proteins into eleven classes according to their transported substrate (i.e., nonselective, water, inorganic cations, inorganic anions, organic anions, organo-oxygens, amino acids and derivatives, other organonitrogens, nucleotides, organic 
heterocyclics, and miscellaneous); to the best of our knowledge, this is the highest number of classes offered by a de novo prediction tool. The TooT-SC method first incorporates the use of evolutionary information by taking 120 similar sequences and constructing an MSA using TM-Coffee. Next, it uses the positional information by filtering out unreliable positions, as determined by the TCS, and then uses the PAAC. The TooT-SC method achieved an overall MCC of 0.82 on an independent testing set, which is a $26 \%$ improvement over the state-of-the-art method. In addition, we evaluated the impact of each factor on the performance by incorporating evolutionary information and filtering out unreliable positions. We observed that the PAAC encoding outperforms other combinational variations. However, it does not show compelling performance on its own; the enhanced performance comes mainly from incorporating evolutionary and positional information.

Analysis of the location of the informative positions reveals that there are more statistically significant informative positions in the TMSs compared to the non-TMSs and there are more statistically significant informative positions that occur close to the TMSs compared to regions far from them.

In moving from the previous gold standard dataset with seven substrate classes to our new dataset with eleven substrate classes, even with the same approach, the overall MCC rose from 0.69 to 0.82. The impact of the positional information is statistically significant more often with the new dataset. The datasets do use different classes, however, we would like to think that the improvement is due to using substrate classes defined in terms of the ChEBI ontology, and selecting proteins in Swiss-Prot with curated GO annotations clearly indicating the substrate in terms of ChEBI.

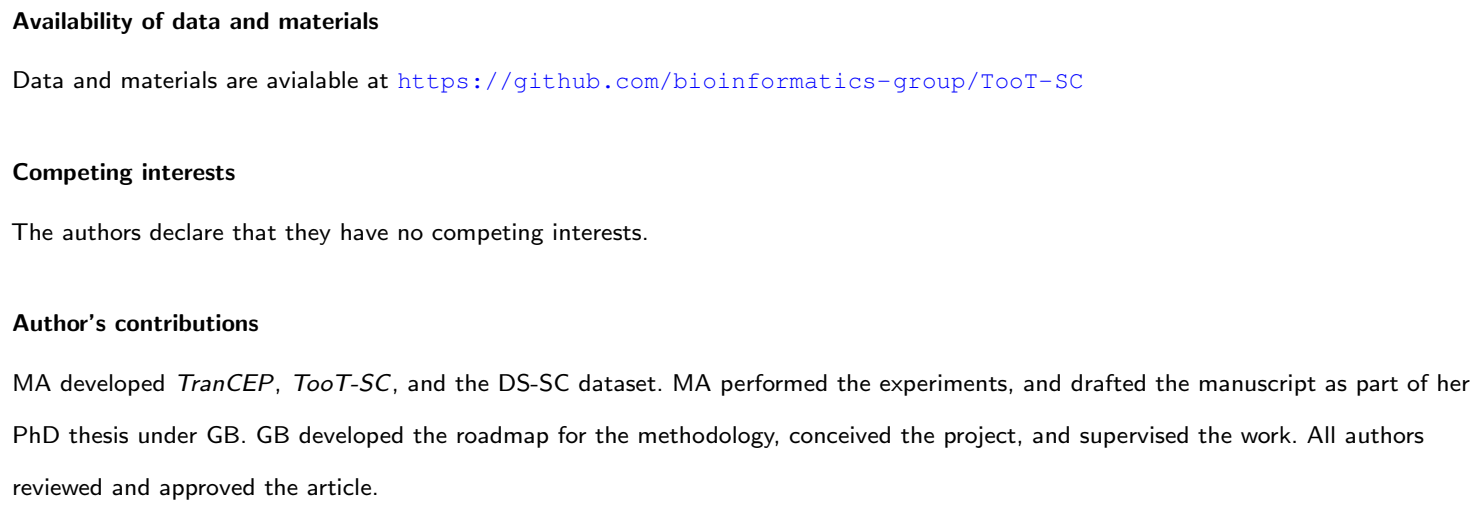




\section{Acknowledgements}

MA was supported by King Saud University in Riyadh, Saudi Arabia, and the Saudi Arabian Cultural Bureau in Canada. GB was partially supported by the NSERC Discovery Grant programme, and by Genome Canada, Genome Québec, and Concordia University for the Bioinformatics and Computational Biology Competition 2017.

\section{Author details}

${ }^{1}$ Department of Computer Science and Software Engineering, Concordia University, Montreal, Canada. ${ }^{2}$ College of Computer and Information Sciences, King Saud University, Riyadh, Saudi Arabia. ${ }^{3}$ Centre for Structural and Functional Genomics, Concordia University, Montreal, Canada.

\section{References}

1. Buehler L. The Structure of Membrane Proteins. In: Cell Membranes. Garland Science; 2015. .

2. Butt AH, Rasool N, Khan YD. A treatise to computational approaches towards prediction of membrane protein and its subtypes. The Journal of Membrane Biology. 2017;250(1):55-76.

3. Lagoa D, Faria JL, Liu F, Cunha E, Henry C, Dias O. TranSyT, the Transport Systems Tracker. bioRxiv. 2021;.

4. Dias O, Rocha M, Ferreira EC, Rocha I. Reconstructing genome-scale metabolic models with merlin. Nucleic Acids Research. 2015;43(8):3899-3910.

5. Capela J, Lagoa D, Rodrigues R, Cunha E, Cruz F, Barbosa A, et al. merlin v4. 0: an updated platform for the reconstruction of high-quality genome-scale metabolic models. bioRxiv. 2021;.

6. Loira N, Zhukova A, Sherman DJ. Pantograph: A template-based method for genome-scale metabolic model reconstruction. Journal of Bioinformatics and Computational Biology. 2015;13(02):1550006.

7. Aplop F, Butler G. TransATH: Transporter prediction via annotation transfer by homology. ARPN Journal of Engineering and Applied Sciences. 2017;12(2).

8. Ho QT, Phan DV, Ou YY, et al. Using word embedding technique to efficiently represent protein sequences for identifying substrate specificities of transporters. Analytical Biochemistry. 2019;577:73-81.

9. Schaadt NS, Christoph J, Helms V. Classifying substrate specificities of membrane transporters from Arabidopsis thaliana. Journal of Chemical Information and Modeling. 2010;50(10):1899-1905.

10. Chen S, Ou Y, Lee T, Gromiha MM. Prediction of transporter targets using efficient RBF networks with PSSM profiles and biochemical properties. Bioinformatics. 2011;27(15):2062-2067.

11. Schaadt N, Helms V. Functional classification of membrane transporters and channels based on filtered TM/non-TM amino acid composition. Biopolymers. 2012;97(7):558-567.

12. Barghash A, Helms $V$. Transferring functional annotations of membrane transporters on the basis of sequence similarity and sequence motifs. BMC Bioinformatics. 2013;14(1):343.

13. Mishra NK, Chang J, Zhao PX. Prediction of membrane transport proteins and their substrate specificities using primary sequence information. PLoS ONE. 2014;9(6):e100278.

14. Alballa M, Butler G. Ontology-based transporter substrate annotation for benchmark datasets. In: 2019 IEEE International Conference on Bioinformatics and Biomedicine (BIBM). IEEE; 2019. p. 2613-2619.

15. Hill DP, Adams N, Bada M, Batchelor C, Berardini TZ, Dietze H, et al. Dovetailing biology and chemistry: integrating the Gene Ontology with the ChEBI chemical ontology. BMC Genomics. 2013;14(1):513.

16. Alballa M, Aplop F, Butler G. TranCEP: Predicting the substrate class of transmembrane transport proteins using compositional, evolutionary, and positional information. PLoS ONE. 2020;15(1):e0227683.

17. Chang JM, Di Tommaso P, Notredame C. TCS: a new multiple sequence alignment reliability measure to estimate alignment accuracy and improve phylogenetic tree reconstruction. Molecular Biology and Evolution. 2014;p. 1625-1637.

18. Alballa M. Predicting transporter proteins and their substrate specificity. Concordia University; 2020. 
bioRxiv preprint doi: https://doi.org/10.1101/2022.01.25.477715; this version posted January 27, 2022. The copyright holder for this preprint (which was not certified by peer review) is the author/funder, who has granted bioRxiv a license to display the preprint in perpetuity. It is made Alballa and Butler available under aCC-BY-NC-ND 4.0 International license.

Page 11 of 16

19. Chang JM, Di Tommaso P, Taly JF, Notredame C. Accurate multiple sequence alignment of transmembrane proteins with PSI-Coffee. BMC Bioinformatics. 2012;13(Suppl 4):S1.

20. Ding Z. Diversified ensemble classifiers for highly imbalanced data learning and its application in bioinformatics. Georgia State University; 2011.

21. Weiss GM, Provost F. Learning when training data are costly: The effect of class distribution on tree induction. Journal of Artificial Intelligence Research. 2003;19:315-354.

22. Bekkar M, Djemaa HK, Alitouche TA. Evaluation measures for models assessment over imbalanced data sets. Journal Of Information Engineering and Applications. 2013;3(10). 
bioRxiv preprint doi: https://doi.org/10.1101/2022.01.25.477715; this version posted January 27, 2022. The copyright holder for this preprint (which was not certified by peer review) is the author/funder, who has granted bioRxiv a license to display the preprint in perpetuity. It is made

Figures

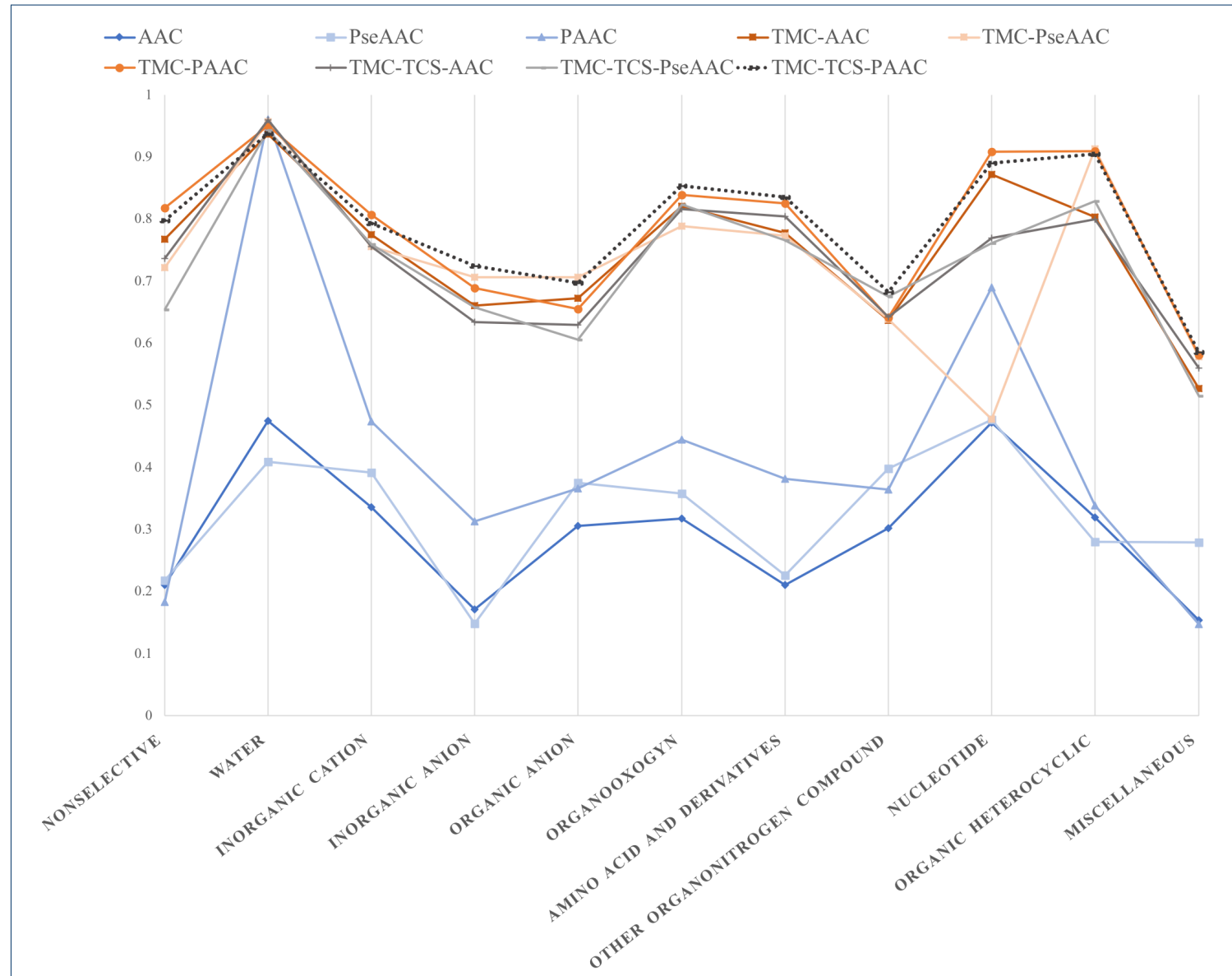

Fig 1. Performance of methods on the substrate classes.

This figure shows the cross-validation MCC performance of the different methods on the eleven substrate classes. The dotted line represents the performance of TooT-SC, which is TCS-TMC-PAAC. 
Table 1. Dataset $D S-S C$

\begin{tabular}{|l||l|c|c|c|}
\hline ID & Substrate class & Training & Testing & Total \\
\hline C1 & Nonselective & 24 & 2 & 26 \\
C2 & Water & 24 & 2 & 26 \\
C3 & Inorganic cations & 541 & 60 & 601 \\
C4 & Inorganic anions & 92 & 10 & 102 \\
C5 & Organic anions & 97 & 10 & 107 \\
C6 & Organo-oxygens & 157 & 17 & 174 \\
C7 & Amino acids and derivatives & 142 & 15 & 157 \\
C8 & Other organonitrogens & 144 & 16 & 160 \\
C9 & Nucleotides & 22 & 2 & 24 \\
C10 & Organic heterocyclics & 34 & 3 & 37 \\
C11 & Miscellaneous & 99 & 11 & 110 \\
\hline \hline \multicolumn{1}{|c|}{ Total } & $\mathbf{1 , 3 7 6}$ & $\mathbf{1 4 8}$ & $\mathbf{1 , 5 2 4}$ \\
\hline
\end{tabular}

Table 2. Overall cross-validation performance of the methods. For each method, the table presents the accuracy and MCC as the mean $\pm S D$ across the ten runs of the 10-fold cross-validation.

\begin{tabular}{|l|c|c|}
\hline Method & Accuracy & MCC \\
\hline TMC-TCS-PAAC & $82.53 \pm 0.12$ & $0.7772 \pm 0.0019$ \\
TMC-PAAC & $81.92 \pm 0.12$ & $0.7695 \pm 0.0014$ \\
TMC-AAC & $79.84 \pm 0.13$ & $0.7430 \pm 0.0014$ \\
TMC-PseAAC & $79.46 \pm 0.30$ & $0.7374 \pm 0.0038$ \\
TMC-TCS-AAC & $79.33 \pm 0.24$ & $0.7360 \pm 0.0035$ \\
TMC-TCS-PseAAC & $79.03 \pm 0.27$ & $0.7324 \pm 0.0037$ \\
PAAC & $58.93 \pm 0.45$ & $0.4610 \pm 0.0069$ \\
PseAAC & $54.80 \pm 0.76$ & $0.3999 \pm 0.0108$ \\
AAC & $52.21 \pm 0.60$ & $0.3628 \pm 0.0091$ \\
\hline
\end{tabular}


Table 3. Detailed TooT-SC performance. The

table presents the performance as the mean $\pm S D$ across the ten runs of the 10 -fold cross-validation.

\begin{tabular}{|c|c|c|c|c|}
\hline Class ID & Sensitivity & Specificity & Accuracy & MCC \\
\hline $\mathrm{C} 1$ & $75.00 \pm 0.00$ & $99.78 \pm 0.00$ & $99.21 \pm 0.00$ & $0.7979 \pm 0.0000$ \\
\hline $\mathrm{C} 2$ & $95.83 \pm 0.00$ & $99.85 \pm 0.00$ & $99.74 \pm 0.00$ & $0.9376 \pm 0.0000$ \\
\hline C3 & $95.19 \pm 0.47$ & $86.92 \pm 0.28$ & $89.36 \pm 0.21$ & $0.7936 \pm 0.0046$ \\
\hline $\mathrm{C} 4$ & $64.35 \pm 1.97$ & $99.24 \pm 0.18$ & $96.38 \pm 0.19$ & $0.7252 \pm 0.0155$ \\
\hline C5 & $68.04 \pm 0.49$ & $98.40 \pm 0.13$ & $95.66 \pm 0.14$ & $0.6974 \pm 0.0084$ \\
\hline C6 & $83.44 \pm 0.52$ & $98.97 \pm 0.12$ & $96.72 \pm 0.15$ & $0.8543 \pm 0.0066$ \\
\hline $\mathrm{C} 7$ & $84.08 \pm 0.95$ & $98.55 \pm 0.16$ & $96.56 \pm 0.18$ & $0.8357 \pm 0.0085$ \\
\hline $\mathrm{C} 8$ & $71.46 \pm 0.95$ & $96.84 \pm 0.27$ & $93.42 \pm 0.22$ & $0.6830 \pm 0.0084$ \\
\hline C9 & $80.91 \pm 1.92$ & $99.98 \pm 0.04$ & $99.61 \pm 0.05$ & $0.8904 \pm 0.0132$ \\
\hline $\mathrm{C} 10$ & $82.35 \pm 0.00$ & $100.00 \pm 0.00$ & $99.47 \pm 0.00$ & $0.9050 \pm 0.0000$ \\
\hline C11 & $55.96 \pm 1.09$ & $97.95 \pm 0.16$ & $94.21 \pm 0.20$ & $0.5858 \pm 0.0136$ \\
\hline \multicolumn{3}{|c|}{ Overall } & $82.53 \pm 0.12$ & $0.7772 \pm 0.0019$ \\
\hline
\end{tabular}

Table 4. Impact of factors on performance for PAAC. This table notes the MCC and the differences in the MCC for the cross-validation performance of the methods using evolutionary information with TM-Coffee, and positional information with TCS. The differences in MCC are shown in the Delta column. The percentage improvement (loss) is also shown. The use of evolutionary information in the form of an MSA on the composition-encoding PAAC improved the MCC by an average of $126.41 \%$. The further use of positional information by filtering out the unreliable columns from the MSA boosted the MCC of the composition encodings by an average of $128.57 \%$.

\begin{tabular}{|c|c|c|c|c|c|c|c|c|c|}
\hline \multirow[t]{2}{*}{$\begin{array}{l}\text { Class } \\
\text { ID }\end{array}$} & \multicolumn{3}{|c|}{ MCC } & \multicolumn{2}{|c|}{$\begin{array}{l}\text { TMC-PAAC } \\
\text { to PAAC }\end{array}$} & \multicolumn{2}{|c|}{$\begin{array}{c}\text { TMC-TCS-PAAC } \\
\text { to PAAC }\end{array}$} & \multicolumn{2}{|c|}{$\begin{array}{l}\text { TMC-TCS-PAAC } \\
\text { to TMC-PAAC }\end{array}$} \\
\hline & PAAC & TMC-PAAC & $\begin{array}{c}\text { TMC-TCS } \\
\text { PAAC }\end{array}$ & Delta & $\%$ & Delta & $\%$ & Delta & $\%$ \\
\hline $\mathrm{C} 1$ & 0.18 & 0.82 & 0.80 & 0.64 & 347.27 & 0.61 & 336.01 & -0.02 & -2.52 \\
\hline $\mathrm{C} 2$ & 0.96 & 0.95 & 0.94 & -0.01 & -1.01 & -0.02 & -2.40 & -0.01 & -1.41 \\
\hline $\mathrm{C} 3$ & 0.47 & 0.81 & 0.79 & 0.33 & 70.12 & 0.32 & 67.25 & -0.01 & -1.68 \\
\hline $\mathrm{C} 4$ & 0.31 & 0.69 & 0.73 & 0.38 & 120.32 & 0.41 & 131.69 & 0.04 & 5.16 \\
\hline C5 & 0.37 & 0.66 & 0.70 & 0.29 & 78.83 & 0.33 & 90.23 & 0.04 & 6.38 \\
\hline C6 & 0.44 & 0.84 & 0.85 & 0.40 & 88.82 & 0.41 & 92.11 & 0.01 & 1.74 \\
\hline $\mathrm{C} 7$ & 0.38 & 0.83 & 0.84 & 0.44 & 116.44 & 0.45 & 119.06 & 0.01 & 1.21 \\
\hline $\mathrm{C} 8$ & 0.36 & 0.64 & 0.68 & 0.28 & 75.77 & 0.32 & 87.23 & 0.04 & 6.52 \\
\hline $\mathrm{C} 9$ & 0.69 & 0.91 & 0.89 & 0.22 & 31.72 & 0.20 & 29.02 & -0.02 & -2.05 \\
\hline $\mathrm{C} 10$ & 0.34 & 0.91 & 0.91 & 0.57 & 168.32 & 0.57 & 166.96 & 0.00 & -0.51 \\
\hline $\mathrm{C} 11$ & 0.15 & 0.58 & 0.59 & 0.43 & 293.97 & 0.44 & 297.15 & 0.00 & 0.81 \\
\hline \multicolumn{4}{|c|}{ Average } & 0.36 & $126.41 \%$ & 0.37 & $128.57 \%$ & 0.01 & $1.24 \%$ \\
\hline
\end{tabular}




\section{Table 5.}

Comparison between TooT-SC and the state-of-art methods. This table presents the performance of the proposed tool TooT-SC built with the complete training set and run on the independent testing set of $D S-S C$ and the corresponding results for the TrSSP and FastTrans methods trained and tested with the same dataset. This table shows the specificity, sensitivity, accuracy and MCC for each of the eleven substrate types; the overall accuracy and MCC; and the macroaverage accuracy and MCC. The overall accuracy was calculated as the number of correct predictions divided by the total number of predictions, and the overall MCC was calculated from the multi-class confusion matrix.

\begin{tabular}{|c|c|c|c|c|c|c|c|c|c|c|c|c|}
\hline \multirow{2}{*}{$\begin{array}{c}\text { Class } \\
\text { ID }\end{array}$} & \multicolumn{3}{|c|}{ Specificity } & \multicolumn{3}{|c|}{ Sensitivity } & \multicolumn{3}{|c|}{ Accuracy } & \multicolumn{3}{|c|}{ MCC } \\
\hline & TrSSP & FastTrans & TooT-SC & TrSSP & FastTrans & TooT-SC & TrSSP & FastTrans & TooT-SC & TrSSP & FastTrans & TooT-SC \\
\hline $\mathrm{C} 1$ & 100.00 & 100.00 & 100.00 & 0.00 & 0.00 & 50.00 & 98.18 & 97.70 & 99.22 & 0.00 & 0.00 & 0.70 \\
\hline C2 & 99.32 & 100.00 & 100.00 & 100.00 & 100.00 & 100.00 & 99.08 & 100.00 & 100.00 & 0.81 & 1.00 & 1.00 \\
\hline C3 & 80.68 & 76.14 & 88.64 & 91.67 & 86.67 & 96.67 & 83.08 & 74.56 & 91.37 & 0.68 & 0.50 & 0.83 \\
\hline $\mathrm{C} 4$ & 98.55 & 95.65 & 100.00 & 60.00 & 40.00 & 70.00 & 94.74 & 87.63 & 97.69 & 0.64 & 0.33 & 0.83 \\
\hline C5 & 98.55 & 97.83 & 97.83 & 80.00 & 50.00 & 90.00 & 96.43 & 91.40 & 96.95 & 0.78 & 0.51 & 0.81 \\
\hline C6 & 96.95 & 96.18 & 97.71 & 64.71 & 35.29 & 76.47 & 91.53 & 84.16 & 94.78 & 0.64 & 0.35 & 0.76 \\
\hline $\mathrm{C} 7$ & 97.74 & 87.97 & 100.00 & 73.33 & 40.00 & 86.67 & 93.91 & 77.27 & 98.45 & 0.72 & 0.20 & 0.92 \\
\hline $\mathrm{C} 8$ & 94.70 & 96.21 & 96.21 & 56.25 & 25.00 & 87.50 & 88.52 & 83.33 & 94.78 & 0.50 & 0.25 & 0.77 \\
\hline C9 & 99.32 & 99.32 & 100.00 & 100.00 & 0.00 & 100.00 & 99.08 & 96.59 & 100.00 & 0.81 & -0.02 & 1.00 \\
\hline $\mathrm{C} 10$ & 98.62 & 100.00 & 100.00 & 33.33 & 66.67 & 100.00 & 96.43 & 98.84 & 100.00 & 0.31 & 0.81 & 1.00 \\
\hline $\mathrm{C} 11$ & 99.27 & 95.62 & 100.00 & 27.27 & 36.36 & 45.45 & 92.31 & 86.73 & 95.49 & 0.42 & 0.31 & 0.66 \\
\hline \multicolumn{7}{|c|}{ Overall } & 72.97 & 57.43 & 85.81 & 0.65 & 0.44 & 0.82 \\
\hline \multicolumn{7}{|c|}{ Macroaverage } & 93.94 & 88.93 & 97.16 & 0.57 & 0.39 & 0.84 \\
\hline
\end{tabular}


bioRxiv preprint doi: https://doi.org/10.1101/2022.01.25.477715; this version posted January 27,2022 . The copyright holder for this preprint

(which was not certified by peer review) is the author/funder, who has granted bioRxiv a license to display the preprint in perpetuity. It is made Iballa and Butler available under aCC-BY-NC-ND 4.0 International license.

Page 16 of 16

\section{Additional Files}

Additional file 1 - Supplementary Material 1

Tables with detailed performance of each of the nine methods on the eleven classes.

Additional file 2 - Supplementary Material 2

Results and discussion on the positional information. 
bioRxiv preprint doi: https://doi.org/10.1101/2022.01.25.477715; this version posted January 27, 2022. The copyright holder for this preprint (which was not certified by peer review) is the author/funder, who has granted bioRxiv a license to display the preprint in perpetuity. It is made available under aCC-BY-NC-ND 4.0 International license.

Page 1 of 3

\section{Supplementary Material 1: Detailed Performance per Class per Method}

This contains the detailed cross-validation performance in substrate specificity prediction. The following tables show the mean $\pm S D$ of the ten different runs of the ten-fold cross validation for each combination of approaches.

Table 1. AAC Performance

\begin{tabular}{|l|c|c|c|c|}
\hline Substrate class & Sensitivity & Specificity & Accuracy & MCC \\
\hline Nonselective & $13.75 \pm 3.95$ & $99.59 \pm 0.05$ & $96.48 \pm 0.20$ & $0.2110 \pm 0.0581$ \\
Water & $37.92 \pm 3.65$ & $99.60 \pm 0.06$ & $97.25 \pm 0.16$ & $0.4748 \pm 0.0372$ \\
Inorganic cations & $87.08 \pm 0.56$ & $61.26 \pm 0.88$ & $64.61 \pm 0.65$ & $0.3364 \pm 0.0124$ \\
Inorganic anions & $13.80 \pm 2.05$ & $98.32 \pm 0.31$ & $87.68 \pm 0.53$ & $0.1716 \pm 0.0349$ \\
Organic anions & $32.06 \pm 1.57$ & $96.90 \pm 0.22$ & $87.18 \pm 0.38$ & $0.3060 \pm 0.0176$ \\
Organo-oxygens & $44.71 \pm 2.91$ & $92.42 \pm 0.38$ & $80.03 \pm 0.61$ & $0.3179 \pm 0.0243$ \\
Amino acids and derivatives & $30.99 \pm 2.68$ & $93.32 \pm 0.50$ & $79.93 \pm 0.79$ & $0.2109 \pm 0.0281$ \\
Other organonitrogens & $33.89 \pm 1.79$ & $95.56 \pm 0.20$ & $82.73 \pm 0.36$ & $0.3022 \pm 0.0162$ \\
Nucleotides & $41.36 \pm 3.98$ & $99.49 \pm 0.10$ & $97.32 \pm 0.23$ & $0.4724 \pm 0.0397$ \\
Organic heterocyclics & $23.82 \pm 4.26$ & $99.37 \pm 0.11$ & $95.43 \pm 0.25$ & $0.3194 \pm 0.0440$ \\
Miscellaneous & $10.91 \pm 2.01$ & $98.66 \pm 0.24$ & $87.22 \pm 0.42$ & $0.1539 \pm 0.0370$ \\
\hline \multicolumn{3}{|c|}{ Overall } & $52.21 \pm 0.60$ & $0.3628 \pm 0.0091$ \\
\hline
\end{tabular}

Table 2. PseAAC Performance

\begin{tabular}{|l|c|c|c|c|}
\hline Substrate class & Sensitivity & Specificity & Accuracy & MCC \\
\hline Nonselective & $12.08 \pm 5.36$ & $99.74 \pm 0.06$ & $96.84 \pm 0.24$ & $0.2176 \pm 0.0897$ \\
Water & $32.92 \pm 4.14$ & $99.51 \pm 0.08$ & $97.08 \pm 0.19$ & $0.4094 \pm 0.0402$ \\
Inorganic cations & $88.37 \pm 0.46$ & $63.65 \pm 0.61$ & $67.30 \pm 0.53$ & $0.3915 \pm 0.0114$ \\
Inorganic anions & $8.15 \pm 1.93$ & $99.21 \pm 0.19$ & $88.84 \pm 0.44$ & $0.1481 \pm 0.0420$ \\
Organic anions & $38.76 \pm 2.02$ & $97.00 \pm 0.38$ & $88.52 \pm 0.60$ & $0.3758 \pm 0.0233$ \\
Organo-oxygens & $48.03 \pm 2.41$ & $92.70 \pm 0.36$ & $81.55 \pm 0.81$ & $0.3578 \pm 0.0271$ \\
Amino acid and derivatives & $32.25 \pm 2.25$ & $93.23 \pm 0.54$ & $80.75 \pm 0.86$ & $0.2259 \pm 0.0270$ \\
Other organonitrogens & $41.94 \pm 1.58$ & $96.07 \pm 0.25$ & $85.10 \pm 0.37$ & $0.3982 \pm 0.0133$ \\
Nucleotides & $42.73 \pm 3.83$ & $99.46 \pm 0.06$ & $97.43 \pm 0.14$ & $0.4774 \pm 0.0313$ \\
Organic heterocyclics & $22.35 \pm 3.16$ & $99.18 \pm 0.18$ & $95.27 \pm 0.27$ & $0.2804 \pm 0.0317$ \\
Miscellaneous & $21.62 \pm 1.19$ & $98.39 \pm 0.17$ & $88.48 \pm 0.30$ & $0.2797 \pm 0.0149$ \\
\hline \multicolumn{3}{|c|}{ Overall } & $54.80 \pm 0.76$ & $0.3999 \pm 0.0108$ \\
\hline
\end{tabular}

Table 3. PAAC Performance

\begin{tabular}{|l|c|c|c|c|}
\hline Substrate class & Sensitivity & Specificity & Accuracy & MCC \\
\hline Nonselective & $10.00 \pm 3.51$ & $99.71 \pm 0.09$ & $96.95 \pm 0.16$ & $0.1830 \pm 0.0587$ \\
Water & $93.33 \pm 2.91$ & $99.99 \pm 0.03$ & $99.78 \pm 0.10$ & $0.9607 \pm 0.0174$ \\
Inorganic cations & $88.98 \pm 0.65$ & $69.21 \pm 0.96$ & $71.91 \pm 0.56$ & $0.4745 \pm 0.0096$ \\
Inorganic anions & $24.24 \pm 2.35$ & $98.46 \pm 0.26$ & $90.06 \pm 0.43$ & $0.3130 \pm 0.0316$ \\
Organic anions & $38.76 \pm 1.77$ & $96.69 \pm 0.40$ & $88.86 \pm 0.49$ & $0.3666 \pm 0.0193$ \\
Organo-oxygens & $54.20 \pm 1.51$ & $93.83 \pm 0.51$ & $84.65 \pm 0.67$ & $0.4447 \pm 0.0211$ \\
Amino acids and derivatives & $47.39 \pm 2.25$ & $93.91 \pm 0.26$ & $84.40 \pm 0.43$ & $0.3815 \pm 0.0193$ \\
Other organonitrogens & $39.58 \pm 2.68$ & $95.54 \pm 0.33$ & $85.11 \pm 0.36$ & $0.3648 \pm 0.0194$ \\
Nucleotides & $68.64 \pm 3.98$ & $99.54 \pm 0.10$ & $98.41 \pm 0.21$ & $0.6901 \pm 0.0371$ \\
Organic heterocyclics & $27.35 \pm 3.41$ & $99.23 \pm 0.08$ & $95.85 \pm 0.13$ & $0.3390 \pm 0.0297$ \\
Miscellaneous & $11.01 \pm 1.93$ & $98.43 \pm 0.20$ & $88.24 \pm 0.40$ & $0.1475 \pm 0.0358$ \\
\hline \multicolumn{3}{|c|}{} & $58.93 \pm 0.45$ & $0.461 \pm 0.0069$ \\
\hline
\end{tabular}


bioRxiv preprint doi: https://doi.org/10.1101/2022.01.25.477715; this version posted January 27, 2022. The copyright holder for this preprint (which was not certified by peer review) is the author/funder, who has granted bioRxiv a license to display the preprint in perpetuity. It is made available under aCC-BY-NC-ND 4.0 International license.

Page 2 of 3

Table 4. TMC-AAC Performance

\begin{tabular}{|l|c|c|c|c|}
\hline Substrate class & Sensitivity & Specificity & Accuracy & MCC \\
\hline Nonselective & $72.08 \pm 4.41$ & $99.73 \pm 0.04$ & $99.07 \pm 0.10$ & $0.7675 \pm 0.0300$ \\
Water & $95.83 \pm 0.00$ & $99.85 \pm 0.00$ & $99.73 \pm 0.00$ & $0.9376 \pm 0.0000$ \\
Inorganic cations & $93.77 \pm 0.28$ & $86.86 \pm 0.49$ & $88.45 \pm 0.29$ & $0.7748 \pm 0.0053$ \\
Inorganic anions & $59.24 \pm 2.31$ & $98.87 \pm 0.12$ & $95.48 \pm 0.23$ & $0.6610 \pm 0.0200$ \\
Organic anions & $68.04 \pm 2.38$ & $97.98 \pm 0.11$ & $95.08 \pm 0.22$ & $0.6727 \pm 0.0175$ \\
Organo-oxygens & $80.83 \pm 0.36$ & $98.61 \pm 0.22$ & $95.89 \pm 0.23$ & $0.8210 \pm 0.0095$ \\
Amino acids and derivatives & $80.07 \pm 0.67$ & $97.84 \pm 0.17$ & $95.23 \pm 0.19$ & $0.7782 \pm 0.0081$ \\
Other organonitrogens & $70.28 \pm 2.14$ & $95.81 \pm 0.28$ & $92.09 \pm 0.26$ & $0.6372 \pm 0.0133$ \\
Nucleotides & $81.82 \pm 0.00$ & $99.90 \pm 0.07$ & $99.52 \pm 0.09$ & $0.8719 \pm 0.0219$ \\
Organic heterocyclics & $72.35 \pm 2.48$ & $99.80 \pm 0.13$ & $98.91 \pm 0.16$ & $0.8032 \pm 0.0277$ \\
Miscellaneous & $46.57 \pm 1.75$ & $98.24 \pm 0.17$ & $93.58 \pm 0.23$ & $0.5269 \pm 0.0186$ \\
\hline \multicolumn{3}{|c|}{ Overall } & $79.84 \pm 0.13$ & $0.743 \pm 0.0014$ \\
\hline
\end{tabular}

Table 5. TMC-PseAAC Performance

\begin{tabular}{|l|c|c|c|c|}
\hline Substrate class & Sensitivity & Specificity & Accuracy & MCC \\
\hline Nonselective & $63.33 \pm 5.12$ & $99.78 \pm 0.06$ & $98.93 \pm 0.14$ & $0.7220 \pm 0.0411$ \\
Water & $95.83 \pm 0.00$ & $99.93 \pm 0.00$ & $99.82 \pm 0.00$ & $0.9574 \pm 0.0000$ \\
Inorganic cations & $94.49 \pm 0.59$ & $84.49 \pm 0.49$ & $87.28 \pm 0.36$ & $0.7561 \pm 0.0072$ \\
Inorganic anions & $59.57 \pm 1.76$ & $99.43 \pm 0.09$ & $96.09 \pm 0.16$ & $0.7065 \pm 0.0143$ \\
Organic anions & $64.54 \pm 1.55$ & $98.94 \pm 0.11$ & $95.80 \pm 0.14$ & $0.7070 \pm 0.0112$ \\
Organo-oxygens & $80.19 \pm 0.82$ & $97.92 \pm 0.23$ & $95.09 \pm 0.21$ & $0.7887 \pm 0.0081$ \\
Amino acids and derivatives & $74.65 \pm 1.29$ & $98.55 \pm 0.18$ & $95.30 \pm 0.23$ & $0.7732 \pm 0.0110$ \\
Other organonitrogens & $72.50 \pm 1.40$ & $95.37 \pm 0.48$ & $91.88 \pm 0.55$ & $0.6390 \pm 0.0207$ \\
Nucleotides & $32.73 \pm 4.18$ & $99.79 \pm 0.10$ & $98.41 \pm 0.12$ & $0.4780 \pm 0.0418$ \\
Organic heterocyclics & $88.82 \pm 4.11$ & $99.87 \pm 0.08$ & $99.49 \pm 0.15$ & $0.9132 \pm 0.0261$ \\
Miscellaneous & $53.43 \pm 1.30$ & $98.18 \pm 0.19$ & $94.03 \pm 0.25$ & $0.5781 \pm 0.0164$ \\
\hline \multicolumn{3}{|c|}{ Overall } & $79.46 \pm 0.30$ & $0.7374 \pm 0.0038$ \\
\hline
\end{tabular}

Table 6. TMC-PAAC Performance

\begin{tabular}{|c|c|c|c|c|}
\hline Substrate class & Sensitivity & Specificity & Accuracy & MCC \\
\hline Nonselective & $75.00 \pm 0.00$ & $99.85 \pm 0.05$ & $99.30 \pm 0.06$ & $0.8185 \pm 0.0141$ \\
\hline Water & $98.33 \pm 2.15$ & $99.85 \pm 0.00$ & $99.79 \pm 0.05$ & $0.9510 \pm 0.0115$ \\
\hline Inorganic cations & $95.25 \pm 0.28$ & $88.26 \pm 0.19$ & $90.11 \pm 0.14$ & $0.8072 \pm 0.0029$ \\
\hline Inorganic anions & $63.80 \pm 1.99$ & $98.80 \pm 0.17$ & $95.86 \pm 0.23$ & $0.6896 \pm 0.0178$ \\
\hline Organic anions & $68.04 \pm 1.75$ & $97.65 \pm 0.06$ & $94.86 \pm 0.18$ & $0.6556 \pm 0.0146$ \\
\hline Organo-oxygens & $83.63 \pm 0.67$ & $98.61 \pm 0.18$ & $96.35 \pm 0.19$ & $0.8397 \pm 0.0079$ \\
\hline Amino acids and derivatives & $82.96 \pm 1.28$ & $98.49 \pm 0.10$ & $96.34 \pm 0.16$ & $0.8257 \pm 0.0085$ \\
\hline Oth & $66.39=$ & $96.70 \pm$ & 92.67 & $0.6412 \pm 0.0084$ \\
\hline Nucleotides & $85.45 \pm 1.92$ & $99.96 \pm 0.06$ & $99.66 \pm 0.07$ & $0.9090 \pm 0.0185$ \\
\hline Organic heterocyclics & $83.24 \pm 4.81$ & $100.00 \pm 0.00$ & $99.50 \pm 0.14$ & $0.9096 \pm 0.0272$ \\
\hline Miscellaneous & $54.34 \pm 1.33$ & $98.09 \pm 0.16$ & $94.18 \pm 0.16$ & $0.5811 \pm 0.0110$ \\
\hline \multicolumn{3}{|c|}{ Overall } & $81.92 \pm 0.12$ & $0.7695 \pm 0.0014$ \\
\hline
\end{tabular}


bioRxiv preprint doi: https://doi.org/10.1101/2022.01.25.477715; this version posted January 27, 2022. The copyright holder for this preprint (which was not certified by peer review) is the author/funder, who has granted bioRxiv a license to display the preprint in perpetuity. It is made available under aCC-BY-NC-ND 4.0 International license.

Page 3 of 3

Table 7. TMC-TCS-AAC Performance

\begin{tabular}{|l|c|c|c|c|}
\hline Substrate class & Sensitivity & Specificity & Accuracy & MCC \\
\hline Nonselective & $70.00 \pm 2.64$ & $99.66 \pm 0.09$ & $98.93 \pm 0.13$ & $0.7365 \pm 0.0288$ \\
Water & $100.00 \pm 0.00$ & $99.85 \pm 0.00$ & $99.82 \pm 0.00$ & $0.9599 \pm 0.0000$ \\
Inorganic cations & $92.88 \pm 0.34$ & $85.96 \pm 0.70$ & $87.52 \pm 0.40$ & $0.7562 \pm 0.0071$ \\
Inorganic anions & $54.57 \pm 1.76$ & $98.98 \pm 0.23$ & $95.21 \pm 0.35$ & $0.6346 \pm 0.0278$ \\
Organic anions & $64.43 \pm 2.89$ & $97.65 \pm 0.17$ & $94.42 \pm 0.33$ & $0.6294 \pm 0.0245$ \\
Organo-oxygens & $83.63 \pm 0.31$ & $98.06 \pm 0.27$ & $95.67 \pm 0.26$ & $0.8168 \pm 0.0097$ \\
Amino acids and derivatives & $82.68 \pm 1.34$ & $98.07 \pm 0.18$ & $95.75 \pm 0.32$ & $0.8049 \pm 0.0149$ \\
Other organonitrogens & $68.54 \pm 0.98$ & $96.35 \pm 0.31$ & $92.36 \pm 0.29$ & $0.6428 \pm 0.0115$ \\
Nucleotide & $70.45 \pm 3.21$ & $99.79 \pm 0.11$ & $99.16 \pm 0.17$ & $0.7698 \pm 0.0415$ \\
Organic heterocyclics & $70.00 \pm 2.32$ & $99.86 \pm 0.04$ & $98.90 \pm 0.09$ & $0.8000 \pm 0.0178$ \\
Miscellaneous & $49.39 \pm 1.99$ & $98.41 \pm 0.17$ & $93.94 \pm 0.29$ & $0.5602 \pm 0.0229$ \\
\hline \multicolumn{3}{|c|}{ Overall } & $79.33 \pm 0.24$ & $0.736 \pm 0.0035$ \\
\hline
\end{tabular}

Table 8. TMC-TCS-PseAAC Performance

\begin{tabular}{|l|c|c|c|c|}
\hline Substrate class & Sensitivity & Specificity & Accuracy & MCC \\
\hline Nonselective & $58.33 \pm 0.00$ & $99.65 \pm 0.04$ & $98.67 \pm 0.04$ & $0.6545 \pm 0.0089$ \\
Water & $95.83 \pm 0.00$ & $99.87 \pm 0.04$ & $99.75 \pm 0.04$ & $0.9435 \pm 0.0096$ \\
Inorganic cations & $93.84 \pm 0.29$ & $85.50 \pm 0.48$ & $87.57 \pm 0.33$ & $0.7594 \pm 0.0061$ \\
Inorganic anions & $58.59 \pm 1.49$ & $98.90 \pm 0.15$ & $95.42 \pm 0.13$ & $0.6585 \pm 0.0092$ \\
Organic anions & $62.58 \pm 1.46$ & $97.46 \pm 0.19$ & $94.05 \pm 0.29$ & $0.6061 \pm 0.0183$ \\
Organo-oxygen s & $80.89 \pm 0.79$ & $98.67 \pm 0.12$ & $95.92 \pm 0.11$ & $0.8239 \pm 0.0047$ \\
Amino acids and derivatives & $78.24 \pm 1.35$ & $97.84 \pm 0.12$ & $94.98 \pm 0.18$ & $0.7660 \pm 0.0095$ \\
Other organonitrogens & $68.96 \pm 1.39$ & $97.15 \pm 0.20$ & $93.16 \pm 0.22$ & $0.6752 \pm 0.0108$ \\
Nucleotides & $76.82 \pm 2.58$ & $99.62 \pm 0.06$ & $99.06 \pm 0.10$ & $0.7618 \pm 0.0232$ \\
Organic heterocyclics & $75.00 \pm 2.08$ & $99.85 \pm 0.05$ & $99.04 \pm 0.08$ & $0.8294 \pm 0.0145$ \\
Miscellaneous & $48.89 \pm 2.44$ & $97.71 \pm 0.18$ & $93.16 \pm 0.33$ & $0.5158 \pm 0.0255$ \\
\hline \multicolumn{3}{|c|}{ Overall } & $79.03 \pm 0.27$ & $0.7324 \pm 0.0037$ \\
\hline
\end{tabular}

Table 9. TMC-TCS-PAAC Performance

\begin{tabular}{|l|c|c|c|c|}
\hline Substrate class & Sensitivity & Specificity & Accuracy & MCC \\
\hline Nonselective & $75.00 \pm 0.00$ & $99.78 \pm 0.00$ & $99.21 \pm 0.00$ & $0.7979 \pm 0.0000$ \\
Water & $95.83 \pm 0.00$ & $99.85 \pm 0.00$ & $99.74 \pm 0.00$ & $0.9376 \pm 0.0000$ \\
Inorganic cations & $95.19 \pm 0.47$ & $86.92 \pm 0.28$ & $89.36 \pm 0.21$ & $0.7936 \pm 0.0046$ \\
Inorganic anions & $64.35 \pm 1.97$ & $99.24 \pm 0.18$ & $96.38 \pm 0.19$ & $0.7252 \pm 0.0155$ \\
Organic anions & $68.04 \pm 0.49$ & $98.40 \pm 0.13$ & $95.66 \pm 0.14$ & $0.6974 \pm 0.0084$ \\
Organo-oxygens & $83.44 \pm 0.52$ & $98.97 \pm 0.12$ & $96.72 \pm 0.15$ & $0.8543 \pm 0.0066$ \\
Amino acids and derivatives & $84.08 \pm 0.95$ & $98.55 \pm 0.16$ & $96.56 \pm 0.18$ & $0.8357 \pm 0.0085$ \\
Other organonitrogens & $71.46 \pm 0.95$ & $96.84 \pm 0.27$ & $93.42 \pm 0.22$ & $0.6830 \pm 0.0084$ \\
Nucleotides & $80.91 \pm 1.92$ & $99.98 \pm 0.04$ & $99.61 \pm 0.05$ & $0.8904 \pm 0.0132$ \\
Organic heterocyclics & $82.35 \pm 0.00$ & $100.00 \pm 0.00$ & $99.47 \pm 0.00$ & $0.9050 \pm 0.0000$ \\
Miscellaneous & $55.96 \pm 1.09$ & $97.95 \pm 0.16$ & $94.21 \pm 0.20$ & $0.5858 \pm 0.0136$ \\
\hline \multicolumn{3}{|c|}{ Overall } & $82.53 \pm 0.12$ & $0.7772 \pm 0.0019$ \\
\hline
\end{tabular}




\section{Supplementary Material 2: Positional Information Analysis}

It is difficult to isolate the exact residues that are key to inferring the substrate class; the results suggest that evolutionary information, obtained by MSA, is the main source for achieving a high prediction performance. In addition, the TCS informative positions (with TCSs $\geq 4$ ) can help to filter out unnecessary noise and obtain a clearer signal to further improve the prediction. Using the TCS informative positions filtered out an average of $31 \% \pm 19 \%$ of the sequence. However, when we attempted to filter out more positions (by using a TCS score cutoff stricter than 4), the performance started to deteriorate.

To visualize the informative positions relative to the hydropathy scale of amino acids, the hydropathy scale proposed by [1] was utilized, and the average hydropathy of each column in the MSA was computed. Higher positive scores indicate that amino acids in that region have hydrophobic properties and are likely located in a transmembrane $\alpha$-helix segment. The TCS of each column in the alignment is noted on the hydropathy plot through color coding. Figure 1 shows diverse examples. The red shades correspond to the informative columns ( $\mathrm{TCS} \geq 4$ ), while the gray and white shades correspond to noninformative columns that are filtered out by TooT-SC. In Figure 1 (a) and (b), the regions with high positive average hydropathy values appear to be more informative than those with lower values. However, in Figure 1 (c) and (d), the difference between the informative positions with high and low hydropathy values is not as clear.

To measure the informative positions relative to different segments of the protein sequence, we divided the protein sequence positions into those in the TMS and those not in the TMS. Those in the TMS were divided into the interior one-third positions, and the remaining exterior positions in the TMS. The non-TMS positions were divided into those near a TMS, that is, within 10 positions, and the remaining positions were considered far from a TMS. The location of the TMS was retrieved from the Swiss-Prot database under the subcellular location topology section. Table 1 shows a breakdown of where the informative positions, as determined by the TCS, are located with respect to the TMS regions.

For instance, in Figure 1 (a), 41.04\% of the residues of the sequence with UniProt-ID Q5 9NP 1 are informative (i.e., correspond to informative columns in the alignment); thus, $58.96 \%$ of this sequence is filtered out. In this case, the residues in the TMSs of this protein are indeed more informative than those of the other proteins, where $100 \%$ of them are informative. On the other hand, only $29.19 \%$ of the residues in non-TMSs are informative. The difference is not as significant in the sequence with UniProt-ID Q9NY37 in Figure 1 (c), where the informative positions in the TMSs are similar to those of non-TMS positions. Details of the sequences in the figure are presented in Table 2.

Table 3 presents a pairwise comparison between informative positions in the TMS and non-TMS regions. The sequences in all of the substrate classes except the $\mathrm{C} 1$ (nonselective) substrate class have significantly more informative positions in the TMS regions than in the non-TMS regions. Similarly, there is a significant difference between the informative positions close to TMSs and positions far from TMSs in all sequences that belong to all substrate classes except the $\mathrm{C} 1$ (nonselective) and $\mathrm{C} 8$ (other organonitrogens) classes, as shown in Table 4. In contrast, there is no difference between the informative positions in the central one-third of the TMS regions and the remaining exterior regions in the sequences that belong to the $\mathrm{C} 1$ (nonselective), $\mathrm{C} 2$ (water), C5 (organic anions), C8 (other organonitrogens), C9 (nucleotides), C10 (organic heterocyclics), and C11 (miscellaneous) classes; the difference is significant in the sequences that belong to the $\mathrm{C} 3$ (inorganic cations), C4 (inorganic anions), C6 (organo-oxygens), and C7 (amino acids and derivatives) classes, as presented in Table 5. 
bioRxiv preprint doi: https://doi.org/10.1101/2022.01.25.477715; this version posted January 27, 2022. The copyright holder for this preprint (which was not certified by peer review) is the author/funder, who has granted bioRxiv a license to display the preprint in perpetuity. It is made available under aCC-BY-NC-ND 4.0 International license.

Page 2 of 5

Author details

References

1. Kyte J, Doolittle RF. A simple method for displaying the hydropathic character of a protein. Journal of Molecular Biology.

1982;157(1):105-132. 


\section{Fig 1. Average Kyte-Doolittle hydropathy of the MSAs with TCSs.}

The figure indicates that the columns highlighted in red are informative and used by TooT-SC. The TooT-SC considers a column to be informative if it has a TCS of at least 4 (shades of red) and filters out the other columns (gray and white). In (a), 259NP 1 contains 251 residues, and the alignment of Q59NP1 with other homologous sequences has 692 columns; only 151 of them are informative (highlighted in shades of red). In (b), Q8BFW9 contains 622 residues, and the alignment of Q8BFW9 with other homologous sequences has 2,414 columns; only 439 of them are informative. In (c), Q9NY37 contains 505 residues, and the alignment of $29 \mathrm{NY} 37$ with other homologous sequences has 2,568 columns; only 508 of them are informative. In (d), Q9Y584 contains 194 residues, and the alignment of Q9Y584 with other homologous sequences has 1,644 columns; only 79 of them are informative.

(a) $259 \mathrm{NP} 1$

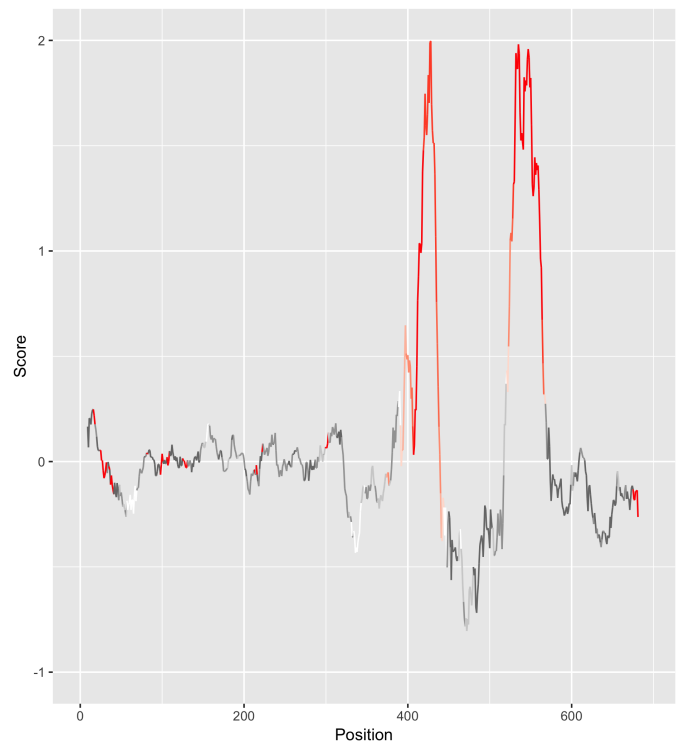

(c) Q9NY37

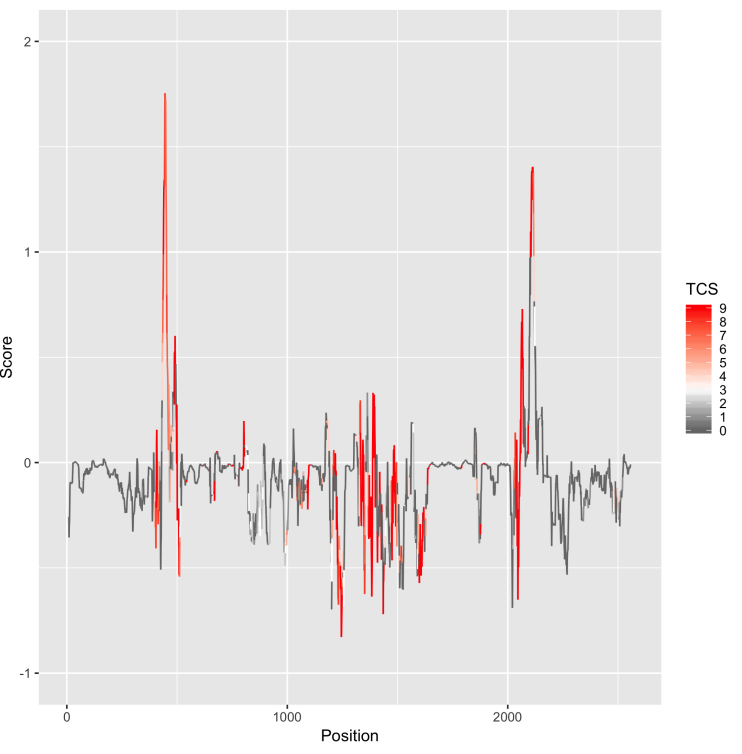

(b) Q8BFW9
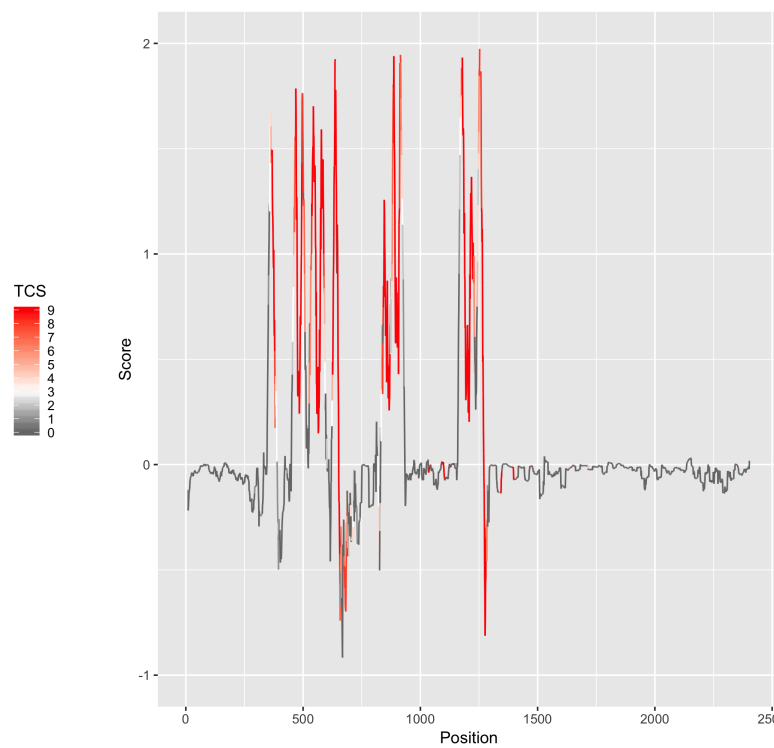

(d) Q9Y584

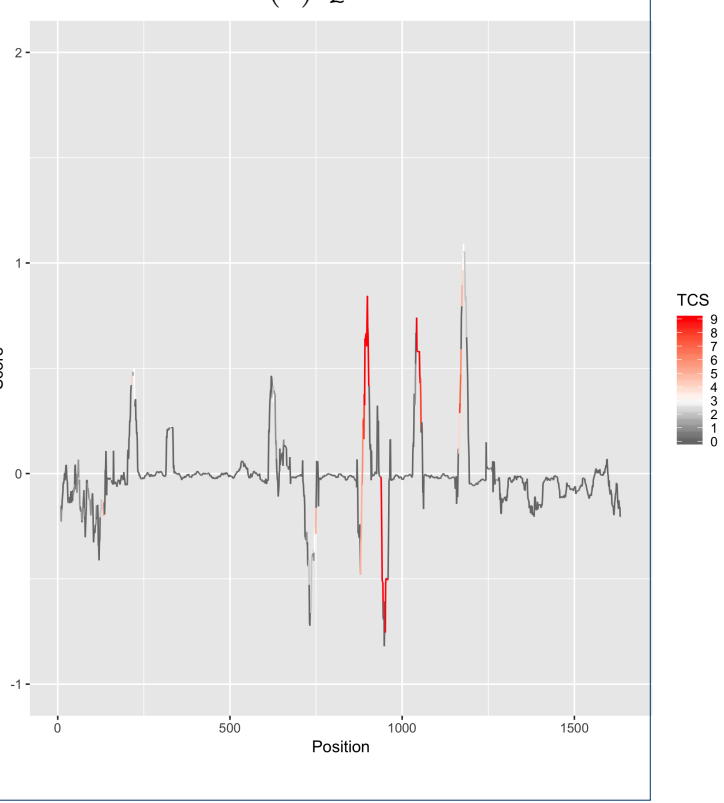


Table 1.

Positional information. This table presents information on the sites retained by the TCS filtering step. For each class of substrates in the dataset, the table presents the average sequence length (SeqLth), the average number of TMS regions (TMS), and the average total number of residues in the TMS regions (TMSLth). It also presents the average of the number of positions retained by the filtering step (Positions: Num) and the average of the number as a percentage of the total sequence length (Positions: \%Seq). It notes the total number of sites that occur in the TMS regions (TMS: Num) and the non-TMS regions (non-TMS: Num). For the TMS regions, it presents the average number of informative sites that occur in the central one-third of the TMS regions (TMS: Interior: Num), and in the remaining exterior regions outside of the central one-third of the TMS regions (TMS: Exterior: Num). For the non-TMS regions, it presents the average number of informative sites that occur close to the TMS regions (within 10 positions of the TMS) (non-TMS: Close: Num) and the remaining sites far from the TMS regions (non-TMS: Far: Num).

\begin{tabular}{|c|c|c|c|c|c|c|c|c|c|c|c|}
\hline \multirow{2}{*}{$\begin{array}{c}\text { Class } \\
\text { ID }\end{array}$} & \multirow[t]{2}{*}{ SeqLth } & \multirow[t]{2}{*}{ TMS } & \multirow[t]{2}{*}{ TMSLth } & \multicolumn{2}{|c|}{ Positions } & \multicolumn{3}{|c|}{ TMS } & \multicolumn{3}{|c|}{ Non-TMS } \\
\hline & & & & Num & $\%$ Seq & Num & $\begin{array}{c}\text { Interior } \\
\text { Num }\end{array}$ & $\begin{array}{c}\text { Exterior } \\
\text { Num }\end{array}$ & Num & $\begin{array}{l}\text { Close } \\
\text { Num }\end{array}$ & $\begin{array}{l}\text { Far } \\
\text { Num }\end{array}$ \\
\hline C1 & 322 & 4 & 81 & 200 & 64.35 & 63 & 22 & 41 & 138 & 35 & 103 \\
\hline $\mathrm{C} 2$ & 273 & 6 & 126 & 203 & 74.72 & 121 & 42 & 79 & 82 & 57 & 25 \\
\hline C3 & 681 & 7 & 149 & 387 & 57.23 & 126 & 45 & 81 & 250 & 65 & 185 \\
\hline C4 & 575 & 8 & 168 & 376 & 62.01 & 142 & 50 & 92 & 215 & 73 & 142 \\
\hline $\mathrm{C} 5$ & 598 & 10 & 203 & 417 & 70.69 & 179 & 62 & 117 & 233 & 91 & 142 \\
\hline C6 & 461 & 10 & 203 & 325 & 70.45 & 177 & 62 & 115 & 144 & 70 & 74 \\
\hline $\mathrm{C} 7$ & 467 & 10 & 206 & 306 & 67.33 & 170 & 59 & 111 & 136 & 83 & 53 \\
\hline $\mathrm{C} 8$ & 537 & 4 & 83 & 347 & 39.34 & 70 & 24 & 46 & 133 & 37 & 96 \\
\hline C9 & 403 & 6 & 129 & 282 & 71.25 & 122 & 43 & 79 & 159 & 79 & 80 \\
\hline C10 & 497 & 12 & 241 & 402 & 79.86 & 218 & 76 & 142 & 183 & 95 & 88 \\
\hline C11 & 639 & 7 & 149 & 349 & 47.44 & 110 & 38 & 72 & 164 & 54 & 110 \\
\hline
\end{tabular}

Table 2. Examples of the informative residue distributions with respect to TMSs and non-TMSs. This table shows the details of individual sequences in Figure 1. The table presents the sequence length (SeqLth), the number of TMS regions (TMS), and the total number of residues in the TMS regions (TMSLth). It also presents the number of informative positions retained by the filtering step (Positions: Num) and that number as a percentage of the total sequence length (Positions: \% Seq). It also denotes the total number of informative sites that occur in the TMS regions (TMS: Num), as well as that number as a percentage of the total TMS length (TMS: \% Seq). In addition, the total number of informative sites that occur in the non-TMS regions (non-TMS: Num) are reported, as well as that number as a percentage of the total non-TMS length (non-TMS: \% Seq).

\begin{tabular}{|c|c|c|c||c|c||c|c||c|c|}
\hline UniProt-ID & SeqLth & TMS & \multicolumn{1}{|c|}{ TMSLth } & \multicolumn{2}{|c|}{ Positions } & \multicolumn{2}{c||}{ TMS } & \multicolumn{2}{c|}{ non-TMS } \\
& & & & Num & $\%$ Seq & Num & $\%$ Seq & Num & $\%$ Seq \\
\hline Q59NP1 & 251 & 2 & 42 & 103 & 41.04 & 42 & 100.00 & 61 & 29.19 \\
\hline Q8BFW9 & 622 & 12 & 252 & 386 & 62.06 & 246 & 97.62 & 140 & 37.84 \\
\hline Q9NY37 & 505 & 2 & 42 & 355 & 70.30 & 31 & 73.81 & 324 & 69.98 \\
\hline Q9Y584 & 194 & 3 & 63 & 78 & 40.21 & 32 & 50.79 & 46 & 35.11 \\
\hline
\end{tabular}


Table 3. Statistical analysis of the informative position rates in the TMS and non-TMS regions. All of the data are reported as the sample mean $\pm S D$. The locations of the TMS regions are shown as annotated by the Swiss-Prot database. There are statistically significant (P-value $<0.0001)$ informative positions in the TMS regions compared to the non-TMS regions in the sequences from all classes except for the nonselective class, where the difference is not significant.

\begin{tabular}{|c||c|c|c|}
\hline Class ID & TMS & non-TMS & P-value \\
\hline C1 & $80.74 \pm 23.46$ & $58.69 \pm 22.43$ & 0.0007 \\
\hline C2 & $95.58 \pm 9.43$ & $57.48 \pm 12.14$ & $<0.0001$ \\
\hline C3 & $78.31 \pm 28.07$ & $49.57 \pm 22.49$ & $<0.0001$ \\
\hline C4 & $79.81 \pm 27.38$ & $53.94 \pm 25.36$ & $<0.0001$ \\
\hline C5 & $88.74 \pm 20.17$ & $60.55 \pm 19.79$ & $<0.0001$ \\
\hline C6 & $85.35 \pm 15.54$ & $56.20 \pm 16.58$ & $<0.0001$ \\
\hline C7 & $81.95 \pm 16.90$ & $55.28 \pm 17.58$ & $<0.0001$ \\
\hline C8 & $46.18 \pm 44.77$ & $34.39 \pm 33.03$ & $<0.0001$ \\
\hline C9 & $94.67 \pm 6.00$ & $59.84 \pm 6.84$ & $<0.0001$ \\
\hline C10 & $90.45 \pm 14.48$ & $69.15 \pm 17.63$ & $<0.0001$ \\
\hline C11 & $55.77 \pm 37.82$ & $41.13 \pm 27.80$ & $<0.0001$ \\
\hline
\end{tabular}

Table 4. Statistical analysis of the informative

position rates close to TMS regions and far from TMS regions. All of the data are reported as the sample mean $\pm S D$. For the non-TMS regions, there are statistically significant (P-value $<0.0001)$ informative positions that occur close to the TMS regions (within 10 positions of the TMS) compared to other regions far from TMS regions in the sequences that belong to most classes, except the $\mathrm{C} 1$ (nonselective) and C8 (Other organonitrogens) classes, where the differences are not significant.

\begin{tabular}{|c||c|c|c|}
\hline Class ID & Close & Far & P-value \\
\hline C1 & $78.24 \pm 23.09$ & $53.31 \pm 26.22$ & 0.002 \\
\hline C2 & $76.58 \pm 10.97$ & $38.59 \pm 15.94$ & $<0.0001$ \\
\hline C3 & $66.82 \pm 26.47$ & $43.77 \pm 22.95$ & $<0.0001$ \\
\hline C4 & $67.26 \pm 26.48$ & $47.89 \pm 26.31$ & $<0.0001$ \\
\hline C5 & $78.15 \pm 19.54$ & $50.94 \pm 21.79$ & $<0.0001$ \\
\hline C6 & $69.96 \pm 14.50$ & $45.09 \pm 19.63$ & $<0.0001$ \\
\hline C7 & $69.18 \pm 17.71$ & $43.39 \pm 20.65$ & $<0.0001$ \\
\hline C8 & $38.10 \pm 41.33$ & $30.53 \pm 30.93$ & 0.001 \\
\hline C9 & $76.60 \pm 06.79$ & $49.55 \pm 11.43$ & $<0.0001$ \\
\hline C10 & $80.52 \pm 14.54$ & $58.05 \pm 23.81$ & $<0.0001$ \\
\hline C11 & $49.91 \pm 33.30$ & $34.75 \pm 26.89$ & $<0.0001$ \\
\hline
\end{tabular}

Table 5. Statistical analysis of the informative position rates in the interior and exterior TMS regions. All of the data are reported as the sample mean $\pm S D$. For the TMS regions, there is no difference between the informative positions in the central one-third of the TMS regions and the remaining exterior regions in the sequences that belong to the $\mathrm{C} 1$ (nonselective), $\mathrm{C} 2$ (water), $\mathrm{C} 5$ (organic anions), C8 (other organonitrogens), C9 (nucleotides), C10 (organic heterocyclics), and C11 (miscellaneous) classes. The difference is significant in the sequences that belong to the C3 (inorganic cations), C4 (inorganic anions), C6 (organo-oxygens), and C7 (amino acids and derivatives) classes.

\begin{tabular}{|c||c|c|c|}
\hline Class ID & Interior & Exterior & P-value \\
\hline C1 & $80.66 \pm 24.30$ & $80.21 \pm 23.55$ & 0.6485 \\
\hline C2 & $98.44 \pm 07.03$ & $94.92 \pm 10.54$ & 0.0003 \\
\hline C3 & $80.92 \pm 28.99$ & $77.48 \pm 28.05$ & $<0.0001$ \\
\hline C4 & $81.74 \pm 28.33$ & $79.10 \pm 27.18$ & $<0.0001$ \\
\hline C5 & $90.09 \pm 19.91$ & $88.25 \pm 20.49$ & 0.0001 \\
\hline C6 & $87.65 \pm 17.15$ & $84.68 \pm 15.50$ & $<0.0001$ \\
\hline C7 & $83.93 \pm 17.22$ & $81.31 \pm 16.97$ & $<0.0001$ \\
\hline C8 & $47.03 \pm 45.76$ & $45.86 \pm 44.65$ & 0.0641 \\
\hline C9 & $97.82 \pm 4.81$ & $93.32 \pm 6.95$ & 0.0001 \\
\hline C10 & $92.73 \pm 14.89$ & $89.75 \pm 14.52$ & 0.0002 \\
\hline C11 & $56.88 \pm 39.33$ & $55.45 \pm 37.52$ & 0.03335 \\
\hline
\end{tabular}

